\title{
Temperature Changes in the Higher Atmosphere
}

\author{
By Prof. E. V. Appleton, F.R.S.
}

$\mathrm{U}^{\mathrm{N}}$ NTIL some years ago, it was generally thought that the temperature of the stratosphere was practically uniform, and of the order of $220^{\circ} \mathrm{K}$. A radical change in such notions was first effected by Lindemann and Dobson who, in 1922, from their study of meteor tracks, showed that the temperature at levels above $60 \mathrm{~km}$. was even higher than that at ground-level. Their conclusions have been adequately confirmed recently in experiments on the anomalous propagation of acoustic waves, on the vertical distribution of ozone with height and, to some extent, by direct temperature measurements in high balloon ascents. There is, then, trustworthy evidence that solar radiation does not pass through the middle part of the atmosphere without warming it, so that we are led to examine, in this connexion, the evidence relating to still higher atmospheric levels, where such heating might be expected to be especially pronounced, since the solar radiation is there most intense and the thermal capacity of the transmission medium least.

Within the last year or so, the study of the diurnal and seasonal changes in upper-atmospheric phenomena by radio methods has indicated that surprisingly high temperatures are attained at great heights $(200-400 \mathrm{~km}$.) and that these temperatures vary in a most pronounced manner. These conclusions have been reached by comparing the observed diurnal and seasonal variations of ionisation with those expected according to a simple theory of photo-ionisation by solar radiation. It is now well known that there are two main regions of ionisation in the upper atmosphere, the lower of which (Region $E$ ) is the KennellyHeaviside layer. Now the maximum ionisation content of the Kennelly-Heaviside layer varies with the hour of the day and with the season of the year much as simple theory predicts. For example, the ratio of summer to winter noon maximum ionisation depends on the zenith distances attained by the sun at noon in summer and in winter. For the latitude of Great Britain, a simple calculation shows that the theoretical value of this ratio should be $1 \cdot 84$, and observations made at the Slough Radio Research Station of the National Physical Laboratory and at the Halley Stewart Laboratory, Hampstead, London, yield an experimental value agreeing very closely with this.

This agreement indicates that, at the level of the Kennelly-Heaviside layer $(100 \mathrm{~km}$.), there is little change of air density or temperature throughout the year. But above the Kennelly-Heaviside layer there is a much more intensely ionised region, Region $F$, and corresponding measurements in this case provide no such agreement with theory. For example, the critical penetration wireless frequency, by way of which the maximum ionisation is measured, is found to be actually less on a summer noon than on a winter noon, indicating that, in contrast to the results obtained for Region $E$, the maximum ionisation in Region $F$ is less on a summer noon than on a winter noon. This result appeared at first sight so startling that some workers concluded that the critical frequency method of measuring atmospheric ionisation was untrustworthy, and that observations made by it could not be accepted. But further work carried out in Great Britain indicates that the method of measurement is trustworthy, and we must face the consequences of these unexpected results. Discrepancies between theory and experiment are always interesting, for from the discrepancy we can often measure the magnitude of the perturbing factor.

Fortunately, in this case, an explanation is to hand. The theory which indicates that summer noon ionisation should be nearly twice that on a winter noon is founded on the assumption that the atmospheric distribution of molecular density with height is constant throughout the year. It is not difficult to show that the abnormally low value of summer noon ionisation density can only be the result of a reduced summer air density at the level in question, otherwise we should have to assume that the solar ionising rays differed in quality from summer to winter. Such a reduced air density can again only be the result of an increased temperature. Putting these ideas into quantitative form, we find that the molecular temperature must be three to nine times as high on a summer noon as on a winter noon, and that the absolute temperature at a level of $300 \mathrm{~km}$. must be at least $1,200^{\circ} \mathrm{K}$. on a summer day.

An equally interesting result emerges from the interpretation of the corresponding nocturnal ionisation measurements. When the sun sets, it is found that the rate of decay of Region $F$ ionisation, which has been proceeding in accordance with the decreasing zenith distance of the sun, is quite suddenly checked on a winter night. It appears as if there were brought into action a 
new source of ionisation, but this is not so. The effect is due to the shrinkage of the outer layer of the atmosphere due to cooling, which brings about a concentration of both molecules and electrons. (Note that wireless methods measure not total ionisation but maximum ionisation per unit volume.) It is found that the concentration of electrons due to upper-atmospheric shrinkage can more than offset the dilution due to recombination processes, and an actual maximum of ionisation content is attained in winter, shortly after midnight. In midsummer no such marked cooling process takes place (for the sun never sets at heights of above $250 \mathrm{~km}$.) and the ionisation (apart from occasional increases which are probably due to a nocturnal ionising agency) is generally found to decay steadily.

The theory of marked temperature changes also suggests an explanation for the curious alteration of structure which Region $F$ undergoes on a summer day. It was shown in 1933 that there is found in our latitudes a subdivision of Region $F$ during daylight in summer. When distinction is necessary we refer to the lower part, which forms a kind of 'step' on the upper part, as Region $F_{1}$, while the upper stratum is referred to as Region $F_{2}$. Since Region $F_{1}$ is found not to exhibit marked temperature changes, it is quite possible that the subdivision is partly, if not wholly, the result of the difference of the temperatures at the two levels,
Region $F_{1}$ being at the lower temperature and Region $F_{z}$ at the higher temperature. According to this view, Region $F_{2}$ is, as it were, part of the main Region $F$ forced upwards by expansion. At night, when the atmosphere shrinks, the two regions tend to merge into a single simple region. It is thus not improbable that differences of tem. perature in the atmosphere, as well as differences in molecular constitution, play a part in causing the composite structure of the ionosphere.

It might appear that these extraordinarily large changes of temperature at high atmospheric levels could not possibly have any influence on wireless communications, but such is not the case. Due to the expansion of the upper atmosphere on a summer day, the maximum electronic density, which determines the shortest wave-length usable in round-the-world communication, is abnormally low, and we are therefore unable to use a valuable range of short wave-length channels. Fortunately, however, Nature provides us to some extent with a form of compensation, for it is found that in summer there is very frequently produced a curious highly-reflecting stratum about the level of Region $E$, which provides abnormally favourable transmission conditions for short waves. But such conditions do not occur daily and so cannot be relied on wholly to remove the unfavourable conditions brought about by the solar heating and expansion of Region $F_{2}$ on a summer day.

\title{
Implementiferous Gravels of the Vaal River at Riverview Estates
}

\author{
By Prof. C. van Riet Lowe, Bureau of Archæology, Dept. of the Interior, Johannesburg
}

Towa

OWARDS the end of April last, Mr. F. W. Webber, chairman of Carrig Diamonds, Ltd., very generously presented a collection of stone implements and a variety of deeply mineralised faunal remains to the Bureau of Archæology recently established at the University of the Witwatersrand. These had been recovered from diamondiferous gravels on the property of Carrig Diamonds, Ltd., at Riverview Estates on the left bank of the Vaal River immediately opposite Windsorton (lat. $28^{\circ} 20^{\prime}$ S., long. $24^{\circ} 44^{\prime} \mathrm{E}$.) shown on the accompanying sketch plan (Fig. 1). As similar remains were still being recovered, I immediately requested Dr. S. H. Haughton, director of the Geological Survey of the Union of South Africa, to accompany me to the site with the object of a detailed investigation. Mr. F. W. Webber had kindly offered to accompany and guide us, and an examination of the area was accordingly carried out during the second week in May.
The ancient gravels were found to be extremely rich in implements and faunal remains, and the occurrence, as a whole, unusually interesting and embracing. Until we are in a position to publish detailed reports, however, the following occurrences are noteworthy.

1. The $60 \mathrm{ft}$. terrace, shown as Site No. 5 on the accompanying 'composite sections' drawing (Fig. 2), comprises a thin layer of gravels that caps the old peneplain some sixty feet above the present flood plain. Inclement weather precluded the possibility of a thorough examination, but in the time at our disposal we were unable to find even traces of the manufacture of stone implements.

$2(a)$. In the lower terrace, actually an old river gravel, marked ' $G$ ' on sections 1, 2, 3 and 4 in Fig. 2, we recovered a few heavily rolled Lower Stellenbosch (Chelles plus Clacton type) tools and a great abundance of rolled and unrolled Upper 